\title{
A FOLLOW-UP STUDY OF THE HUMAN CLASS AND SUBCLASS ANTIBODY RESPONSE DEVELOPED AGAINST THE ADULT STAGE OF TRICHINELLA SPIRALIS
}

\author{
CHAPA-RUIZ M.R. ${ }^{* 1}$, GONZÁLEZ-PANTALEÓN D.*, MORALES-GALÁN A.*, CONTRERAS-RAMOS A.*, \\ SALINAS-TOBÓN M.R.* ${ }^{* 1} \&$ MARTÍNEZ Y ZAMORA R.**
}

\begin{abstract}
Summary :
We report the analysis by ELISA of class and subclass antibody response against a total soluble extract from $T$. spiralis adult stage (TSE-A) during a year after the infection in 17 symptomatic trichinellosis patients (SI) and five asymptomatic individual (AI) involved in an outbreak of trichinellosis occurred in the State of Mexico. Serum samples from 20 healthy individuals $(H I)$ and 24 patients with other parasitosis were included as control. All SI showed a polyisotypic antibody response against the TSE-A, during the infection. Higher response of $\lg A, \lg E$, $\lg M$ were detected in SI during the acute phase of the infection, but only lgE remained at high levels all along the infection. None or a lower reactivity against TSE-A was observed in sera from Al and from $\mathrm{HI}$. Some patients with trichuriosis and ascariosis showed a higher cross-reactivity against TSE-A when $\lg G$ and their subclasses were analyzed.
\end{abstract}

KEY WORDS : Trichinella, adult stage, human, antibody, diagnosis.

I n some parasitic diseases, the analysis of human class and subclass antibody responses has improved the serological methods for diagnosis (Brito et al., 2000) and conferred prognosis value (Hu et al., 1999). Based on this, we analyzed the human antibody response against Trichinella spiralis adult stage with the aim to determine the usefulness of isotypic and subtypic antibody detection in the diagnosis of human trichinellosis.

\section{MATERIAL AND METHODS}

\section{PARASITE AND INFECTION}

T spiralis (pig strain) was maintained by serial passage in outbred $\mathrm{BALB} / \mathrm{c}$ mice. Infective muscle larvae (ML) and adult worms (A) were collected as described by Dennis et al. (1970).

\footnotetext{
* Immunology Department, Escuela Nacional de Ciencias Biológicas, I.P.N. Apdo. Postal CON-238. Mexico, D.F. c.p. 06400 Mexico.

** Hospital General de Zona No. 27, I.M.S.S. Eje Central Lázaro Cárdenas No. 445, Mexico, D.F. 06900 Mexico.

Correspondence: M Sc María del Rosario Chapa Ruiz. Apdo. Postal CON-238. Mexico, D.F. c.p. 06400 Mexico.

Fax: (5) 729-6000 ext. 62489 - E-mail: mchapa@redipn.ipn.mx
}

${ }^{1}$ Fellows of COFAA. Supported by CGPI, I.P.N.

\section{ANTIGEN}

A total soluble extract of adults (TSE-A) was obtained in $10 \mathrm{mM}$ Tris- $\mathrm{HCl}, \mathrm{pH} 8.13$ added with protease inhibitors as described Parkhouse, 1984.

\section{SERUM SAMPLES}

These sera were collected from 22 individuals involved in an outbreak of trichinellosis occurred in the State of Mexico. Seventeen out of twenty two individuals displayed clinical symptoms of the disease (SI); 13 of them had confirmed parasite infection by muscle biopsy $\left(\mathrm{SB}^{+}\right)$and four were negative $\left(\mathrm{SB}^{-}\right)$while the remaining five did not exhibit any symptom and were negative by ELISA (AI). Serum samples from these individuals were collected at weeks 3, 4, 5, 7, 12, 15, 37, and 57 postinfection (pi). Control serum samples were collected from 20 healthy individuals (HI), and from 39 patients infected with other parasites (PI), whose diagnosis were confirmed by parasitological or serological tests.

\section{ELISA ASSAYS}

These assays were performed to detect class and subclass antibody responses using $5 \mu \mathrm{g} / \mathrm{mL}$ of TSE-A and serum samples were diluted at 1:320 for IgM, IgG and IgG subclasses detection or 1:100 for IgA and IgE. Indirect ELISA (I-ELISA) assays were carried out to detect IgM and IgG antibodies as described by Chapa-Ruiz et al., 1989, using a peroxidase-conjugated goat antihuman IgM and IgG (heavy-chain reactive, Cappel Lab.) at 1:20000 and 1:5000 dilutions, respectively. Indirect amplified ELISA (Ia-ELISA) assays were carried out to analyze IgE, IgA, and IgG subclasses according to Au et al. (1983) and Ljungström et al. (1988). Goat anti-human IgE and IgA (heavy-chain reactive Cappel, Lab.) were diluted 1:32000 and 1:2000 respectively, and peroxidase-conjugated rabbit anti-goat IgG (heavychain reactive Cappel, Lab.) diluted 1:8000 for IgE and IgA detection. Monoclonal antibodies (MoAbs) to human $\operatorname{IgG}_{1}, \operatorname{IgG}_{2}, \operatorname{IgG}_{3}$ or $\operatorname{IgG}_{4}$ (Boehringer, Mannheim) were used at 1:2000 dilution. Goat anti-mouse IgG (heavy-chain reactive Cappel, Lab.) was diluted 1:8000, while peroxidase-conjugated rabitt anti-goat 

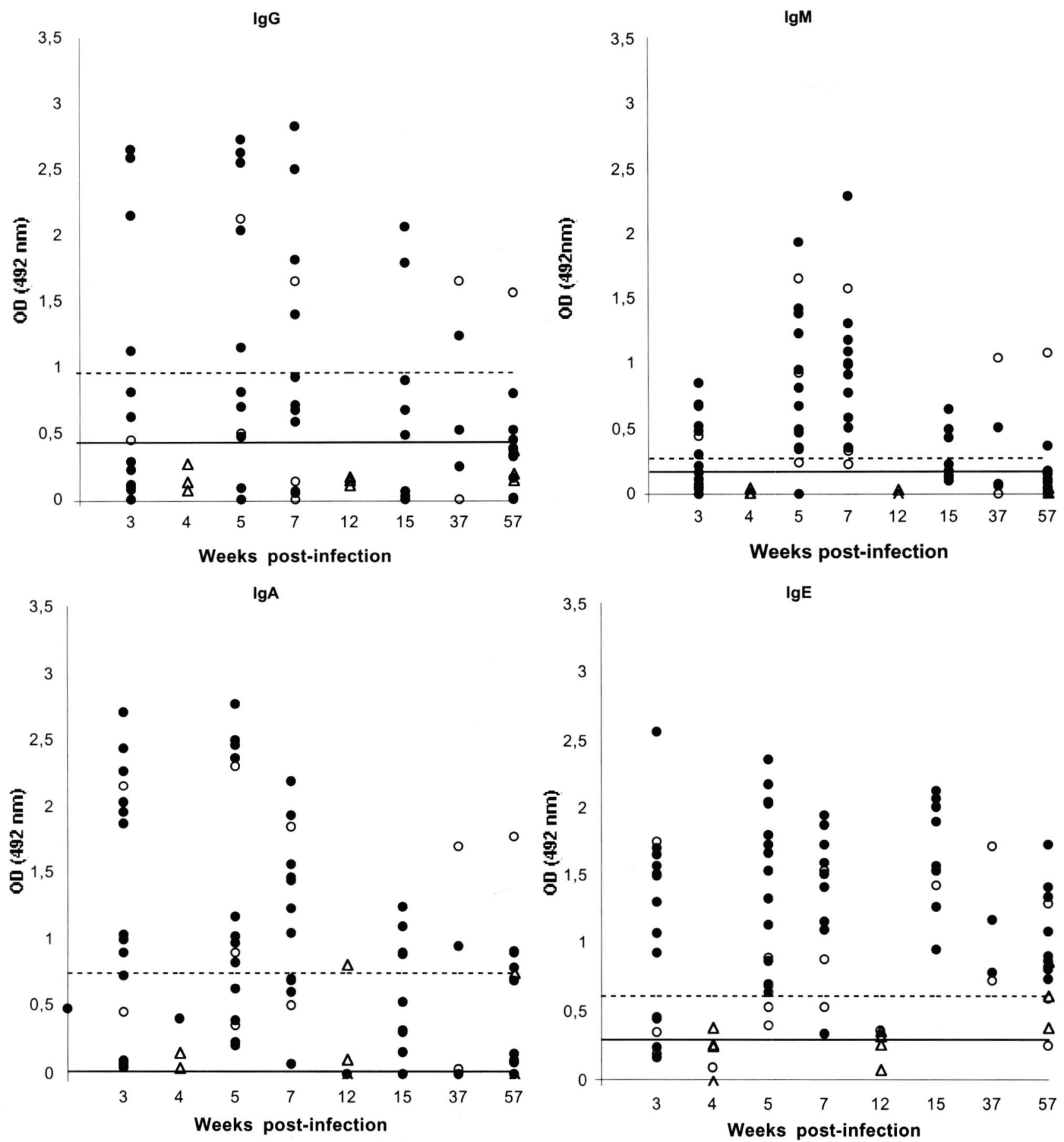

Fig. 1. - Analysis by ELISA of class antibody response against the adult stage of Trichinella spiralis in trichinellosis patients during the infection.

I-ELISA assays were carried out to detect IgM and IgG antibodies as described in material and methods. Serum samples from symptomatic trichinellosis patients with: $\bullet$ positive or $\bigcirc$ negative biopsy and from $\nabla$ asymptomatic individuals, were analyzed. Doted line: cut-off value (media $+3 \sigma$ from patients with other parasitosis). Line: cut-off value from healthy individuals. 

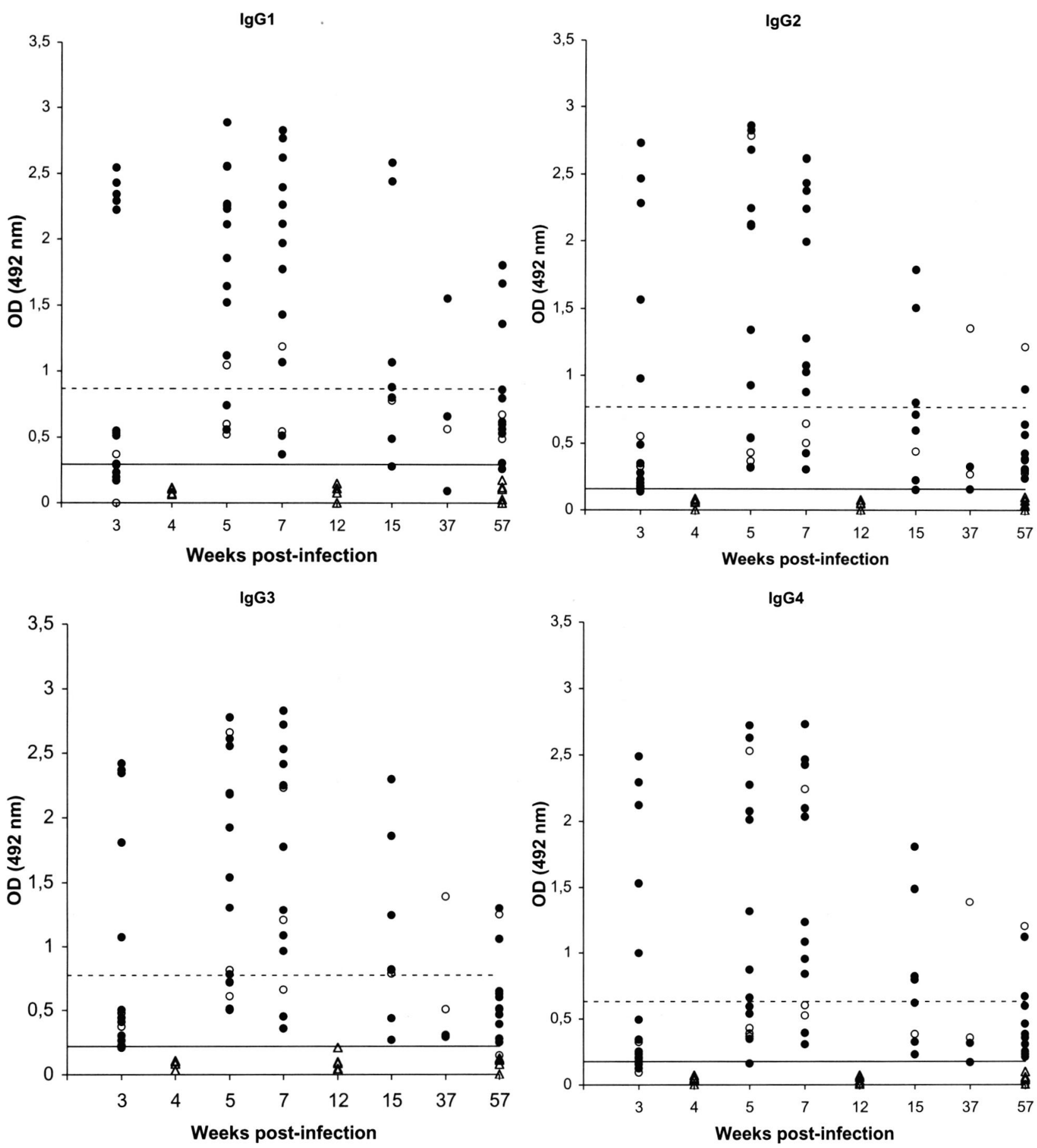

Fig. 2. Analysis by ELISA of subclass antibody response against the adult stage of Trichinella spiralis in trichinellosis patients during the infection.

Ia-ELISA assays were carried out to detect IgA and IgE antibodies as described in material and methods. Serum samples from symptomatic trichinellosis patients with: $\bullet$ positive or $\bigcirc$ negative biopsy and from $\nabla$ asymptomatic individuals, were analyzed. Doted line: cut-off value (media $+3 \sigma$ from patients with other parasitosis). Line: cut-off value from healthy individuals. 
IgG was used at 1:16000 dilution. Absorbances were determined by ELISA plate reader (Dynatech, Industries) at $492 \mathrm{~nm}$.

\section{RESULTS}

This study revealed that all immunoglobulin isotypes and subclasses of IgG were detected in SI at week 3 pi, reached a peak by weeks 5 or $7 \mathrm{pi}$ and diminished from week 15 up to the end of the study except for IgE, which remained at high levels during infection (Figures 1 and 2, respectively). These antibody responses were variable among SI with regard to time of analysis. In a previous study (Salinas et al., 1996) negative serum samples from AI for TSL-1 antigens were tested in this work to demonstrate early production of antibodies to adults. Lower reactivity against TSE-A was detected in serum samples from AI and comparable to that from $\mathrm{HI}(\mathrm{OD}<0.3)$ (Figures 1 and 2). Higher cross-reactivity against TSE-A were obtained in PI $(\mathrm{OD}<0.86)$ with ascariosis and trichuriosis when IgG and their subclasses, IgA and IgE were determined. ELISA assays revealed that a higher number of trichinellosis SI were detected with: IgA and IgE (69 and $62 \%$, respectively) at week $3 \mathrm{pi}$, IgE and IgM (88\% and $86 \%$, respectively) at week 5 pi, IgM (93\%) at week 7 pi and IgE (values around $100 \%$ ) from weeks 15 up to 57 when mean absorbance $+3 \sigma$ from PI were taken as cut-off values.

\section{DISCUSSION}

The analysis of the human class and subclass antibody response against adults of $T$. spiralis by ELISA revealed that adults antigens induce a high polyisotypic and polysubtypic antibody response in humans during the acute phase of the infection. This response showed to be variable among analyzed individuals and in each individual along the study. These could be due to genetic differences in histocompatibility antigens as detected in mice infected with the parasite (Almond et al., 1986).

The analysis of the class and subclass antibody response against TSE-A and TSL- 1 antigens by ELISA in the same group of patients revealed that adults antigens induce a higher polyisotypic and polysubtypic response during the acute phase of the infection, as the one observed against TSL-1 antigens from ML (Salinas et al., 1996). Nevertheless, the response of SI against the TSE-A diminished from 15 up to 57 weeks pi, except for IgE, meanwhile the response against TSL- 1 antigens remained elevated in the same period. This suggests that adult worm and TSL-1 antigens share epitopes as demons- trated by Takahashi \& Homan (1993). These epitopes were recognized by IgE but not by the other isotypes and subtypes during the chronic phase of the disease. The high levels of isotypes and subtypes detected during acute phase of the infection in SI may be associated with the adults development in the intestine. IgE produced in rats gut after T. spiralis infection is preferentially transported to the gut lumen rather than to circulation (Negrao-Correa et al., 1996) and consistently higher in rat strains that eliminate T. spiralis worms earlier in the infection (Negrao-Correa et al., 1999). According to this, a similar IgE production and transport in human gut may occur, as low levels of IgE and IgA were detected in serum samples from trichinellosis patients by the methodology used in this study.

In SI, IgM response developed against adults was the most specific. It suggests that glycosilated antigens of adults are specific ones.

On the other hand, AI showed no reactivity to adults antigens; this suggests that AI were not infected with T. spiralis or the level of the infection was so low to elicit a detectable antibody by the techniques employed in this work.

In conclusion, the detection of IgA or IgE against antigens from T. spiralis adults is useful for the early diagnosis of human trichinellosis. Therefore, specific antigens from TSE-A recognized by these classes of antibodies could be identified and isolated in order to improve the early diagnosis of human trichinellosis. On the other hand, the detection of IgA and IgM against TSE-A could be used as markers of acute phase of the T. spiralis infection.

\section{REFERENCES}

Almond N.M. \& Parkhouse R.M.E. Immunoglobulin Class specific responses to biochemical defined antigens of Trichinella spiralis. Parasite Immunology, 1986, 8, 391-406.

Au A.C.S., Ko R.C., Simon J.W., Ridell N.J., WONG F.W.T. \& TEMPLer M.J. Study of acute trichinosis in Ghurkas: specificity and sensitivity of enzyme-linked immunosorbent assay for IgM and IgE antibodies to Trichinella larval antigens in diagnosis. Transaction of the Royal Society of Tropical Medicine and Hygiene, 1983, 77, 412-417.

Brito C.F., Fonseca C.T., Goes A.M., Azevedo V., Simpson A.J. \& Oliveira S.C. Human $\operatorname{IgG}_{1}$ and $\mathrm{IgG}_{3}$ recognition of Schistosoma mansoni $14 \mathrm{kDa}$ fatty acid-binding recombinant protein. Parasite Immunology, 2000, 22, 41-48.

Chapa-Ruiz M.R., Salinas-Tobon M.R., Martinez-Marañon R., Cedillo R. \& Garcia-Latorre E. Diagnosis of human trichinosis by indirect enzyme-linked immunosorbent assay (ELISA). Revista Latinoamericana de Microbiologia, 1989, 31, 133-136.

Dennis D.T., Despommier D. \& Davis N.J. Infectivity of the new born larva of Trichinella spiralis in the rat. Journal of Parasitology, 1970, 56, 974-977. 
Hu M., Kririnoki M., Yokor H., Kawai S., Chigusa Y. \& MatSUDA H. Human antibody isotype response to Schistosoma japonincum egg antigens. Southeast Asian Journal of Tropical Medicine Public Health, 1999, 30, 24-28.

Ljungström I., Hammarström L., KociecKa W. \& Smith C.I.E. The sequential appearance of $\operatorname{IgG}$ subclasses and $\operatorname{IgE}$ during the course of Trichinella spiralis infection. Clinical Experimental Immunology, 1988, 74, 230-235.

Negrao-Correa D., Adams L.S. \& Bell R.G. Intestinal transport and catabolism of IgE. A major blood independent pathway of IgE dissemination during a Trichinella spiralis infection of rats. The Journal of Immunology, 1996, 157, 4037-4044.

Negrao-Correa D., Adams L.S. \& Bell R.G. Variability of the intestinal immunoglobulin $\mathrm{E}$ response of rats to infection with Trichinella spiralis, Heligmosomoides polygyrus or Nippostrongylus brasiliensis. Parasite Immunology, 1999, 21, 287-297

PARKHouse R.M.E. Immunopurification. British Medical Bulletin, 1984, 40, 297-301.

Salinas-Tobón M.R., Mendez-Loredo B., Alcantara-GonZalez N., Valdez-Cruz C., Martinez y Zamora R., OrtegaPierres G. \& Chapa Ruiz M.R. Class and subclass specific antibody responses to TSL-1 antigens during Trichinella spiralis human infection, in: Trichinellosis. Proceedings of the Ninth International Conference on Trichinellosis. Ortega-Pierres G., Gamble R., van Knapen F. \& Wakelin D. (eds). CINVESTAV, IPN. Mexico, D.F., 1996, 453-462.

TAKAHASHI Y. \& HOMAN W.L. Subcellular localization of antigens recognized by monoclonal antibodies against Trichinella spiralis larvae group 1 (TSL-1) antigens, in: Trichinellosis. Proceedings of the Eighth International Conference on Trichinellosis. Campbell W.C., Pozio E. \& Bruschi F. (eds). Istituto Superiore di Sanita, Rome, 1993, 279-282. 